\title{
A ESCRITA CIENTÍFICA EN GALEGO NO NOVO SEMINARIO DE ESTUDOS GALEGOS
}

Francisco Díaz-Fierros Viqueira

Presidente da Xunta Reitora do Seminario de Estudos Galegos 

No ano 1979 fúndase, promovido por Díaz Pardo, o novo Seminario de Estudos Galegos (SEG). A gran maioría dos seus primeiros socios, ademais dos integrantes vivos do vello SEG, estaba constituída por investigadores, técnicos e profesores universitarios. Concibido como unha institución interdisciplinar, organizouse inicialmente en 17 áreas que abranguían desde as ciencias ás humanidades, pasando pola historia, economía, pedagoxía, etc. De todos os xeitos, foron sobre todo as áreas correspondentes ás ciencias aplicadas as que lle deron carácter á primeira etapa (1979-1987) do novo Seminario. En 1979 constitúese a Área de Xeoloxía, en 1982 a de Ciencias Agrarias, en 1983 a de Ciencias Marińas e en 1984 a de Ciencias Biolóxicas. Unha das posibles razóns deste dominio das áreas de ciencias da natureza fronte ás outras podería estar nun contencioso que se xerou co Instituto Padre Sarmiento no relativo á propiedade dos bens do antigo SEG. Os posibles integrantes das novas áreas de historia, artes, pensamento, etc. tiñan, en xeral, vencellos tradicionais co Padre Sarmiento que puideron actuar como freo para a súa incorporación ao novo SEG.

Por outra parte, no caso de áreas como as de ciencias agrarias ou marińas, con investigadores repartidos entre institucións que non tiñan en xeral unha tradición de colaboración consolidada, o novo SEG ofrecía un campo de xogo neutral no que se podían poñer en común temas compartidos polos investigadores das diferentes institucións sen grandes receos corporativos:

O carácter neutral e non comprometido cos intereses das diferentes organizacións de investigación, do Seminario de Estudos Galegos, semellaba convertilo en unha institución válida para potenciar istes encontros entre os investigadores. Por outra banda o fondo significado galego da institución, avalado polo seu inesquencible precedente histórico, enmarcaba os encontros en unha rexa conciencia colectiva de traballar polo desenvolvemento económico do país, presentándose a tarefa investigadora, no seu horizonte, como un compromiso ético urxente coa nosa realidade («Limiar", I Xornadas de Estudo sobor dos Recursos Básicos da Agricultura Galega. Cuadernos da Área de Ciencias Agrarias, 4. Publ. Sem. Est. Galegos, 1983).

Por outra parte, a temática aplicada tińa, naqueles tempos, máis resonancias entre os investigadores que na actualidade, que na súa inmensa maioría están obsesivamente dedicados a implementar o seu currículo con publicacións en inglés e 
con temas de atractivo internacional, que non sempre coinciden coas necesidades máis perentorias dos diferentes sectores produtivos do país.

As publicacións do novo SEG chegaron no conxunto das áreas ás cento setenta (Díaz-Fierros, 2006) ${ }^{1}$, e dividíanse normalmente en monografías e actas das xornadas de estudo. $\mathrm{O}$ uso do galego foi relativamente significativo no conxunto das áreas de ciencias e técnicas, e variaba moito dunhas a outras. Así, por exemplo, a de xeoloxía, polo seu carácter de referente dos especialistas do oeste-noroeste peninsular, utilizou moi pouco o galego; mentres que, polo contrario, a de bioloxía realizou case toda a súa produción nesa lingua. As ciencias agrarias e marińas situábanse nunha posición intermedia, e dependía moito o uso do galego do carácter das xornadas ou monografías.

Pódese definir 1987 como o inicio dunha nova etapa do Seminario caracterizada pola creación do primeiro grupo de traballo interdisciplinar que se dedicou á Historia das ciencias e das técnicas, así como pola creación da Área de historia medieval, que rachaba co tradicional receo fronte a estas temáticas. $\mathrm{O}$ grupo de traballo interdisciplinar de Historia das ciencias e das técnicas denominado «Ramón Aller», en lembranza do seu traballo pioneiro a prol do galego como medio de expresión científica, puxo en marcha un proxecto de realización dun dicionario biobliográfico de científicos galegos que deu orixe a dous volumes $(1993,2005)$ e que na actualidade está en fase dunha nova reedición, ampliada e mellorada. Así mesmo, editou a revista Ingenium, dedicada á historia das ciencias en Galicia, con nove volumes editados. O Dicionario editouse en galego e, no caso da revista, a porcentaxe de artigos escritos en galego superaba amplamente o $50 \%$.

En resumo, pódese sinalar que a etapa do novo SEG supuxo unha contribución importante á publicación científica en galego, pois nas actas das xornadas de debate, nos inventarios e nas revistas que promoveu apareceron moitos artigos orixinais nos que se presentaban por primeira vez datos experimentais, dun xeito sistemático, neste idioma. Aínda que está por facer un inventario polo miúdo deste tipo de publicacións, non constituíron un feito anecdótico nin illado. Así mesmo, publicáronse diversas monografías que supuxeron importantes artigos de revisión ou de alta divulgación científica.

1 F. Díaz-Fierros: «O legado do Seminario de Estudos Galegos e o compromiso ético-social da cultura e a investigación", en Isaac Díaz Pardo. Creación e compromiso na Galicia do século XX. A Coruña, Deputación, 2006. 
Todo iso foi posible, en primeiro lugar, grazas á xenerosidade do Grupo Sargadelos, que lideraba Isaac Díaz Pardo. A súa editorial de Ediciós do Castro e as dependencias do Instituto Galego de Información, en Santiago, e Do Castro, en Sada, estiveron sempre, sen ningún xeito de restricións, ao servizo do novo SEG. En segundo lugar, tampouco se pode desbotar o clima de ilusión e de afáns rexeneracionistas que existía nas décadas dos setenta e oitenta. E nas que se formaron, sen dúbidas, os elementos máis activos do novo SEG, moitos dos cales compartían traballos con grupos de perfil máis activista de rúa, como podían ser as sociedades ecoloxistas ou as asociacións culturais. E tampouco se pode ignorar que as carreiras investigadoras ou docentes de moitos dos integrantes destas áreas non estaban sometidas ás presións de traballo actuais, que priman para a promoción profesional as publicacións en inglés e con temas na maioría dos casos bastante afastados das temáticas aplicadas.

Todo este conxunto de factores fixo posible a xeira do novo SEG. Case trinta anos vizosos, nos que un fato de científicos e técnicos, amplo no seu número e variado na súa composición, tentaron, nun exercicio de xenerosidade, dedicarlle parte do seu tempo á causa de Galicia. É posible hoxe poñer en marcha unha experiencia semellante? Unha experiencia que podería ser equivalente na ilusión compartida que se vivía e nos obxectivos últimos que se procuraban, pero, sen dúbida, diferente nos medios que se terían que utilizar, entre os que «a rede» sería claramente a canle de elección.

Os novos investigadores e docentes poderían dedicarlle unha parte do seu tempo a estas tarefas? Pensamos que os condicionantes profesionais actuais non son doados para estas utopías e os que veñen probablemente non serán mellores, pero a historia non está escrita e, ás veces, achega sorpresas inesperadas. En calquera caso, o futuro segue aberto. 
Organigrama do novo Seminario de Estudos Galegos (1979)

\section{SINOPSE DO NOVO SEMINARIO DE ESTU DOS GALEGOS SEGUN O PROXECTOde1979}

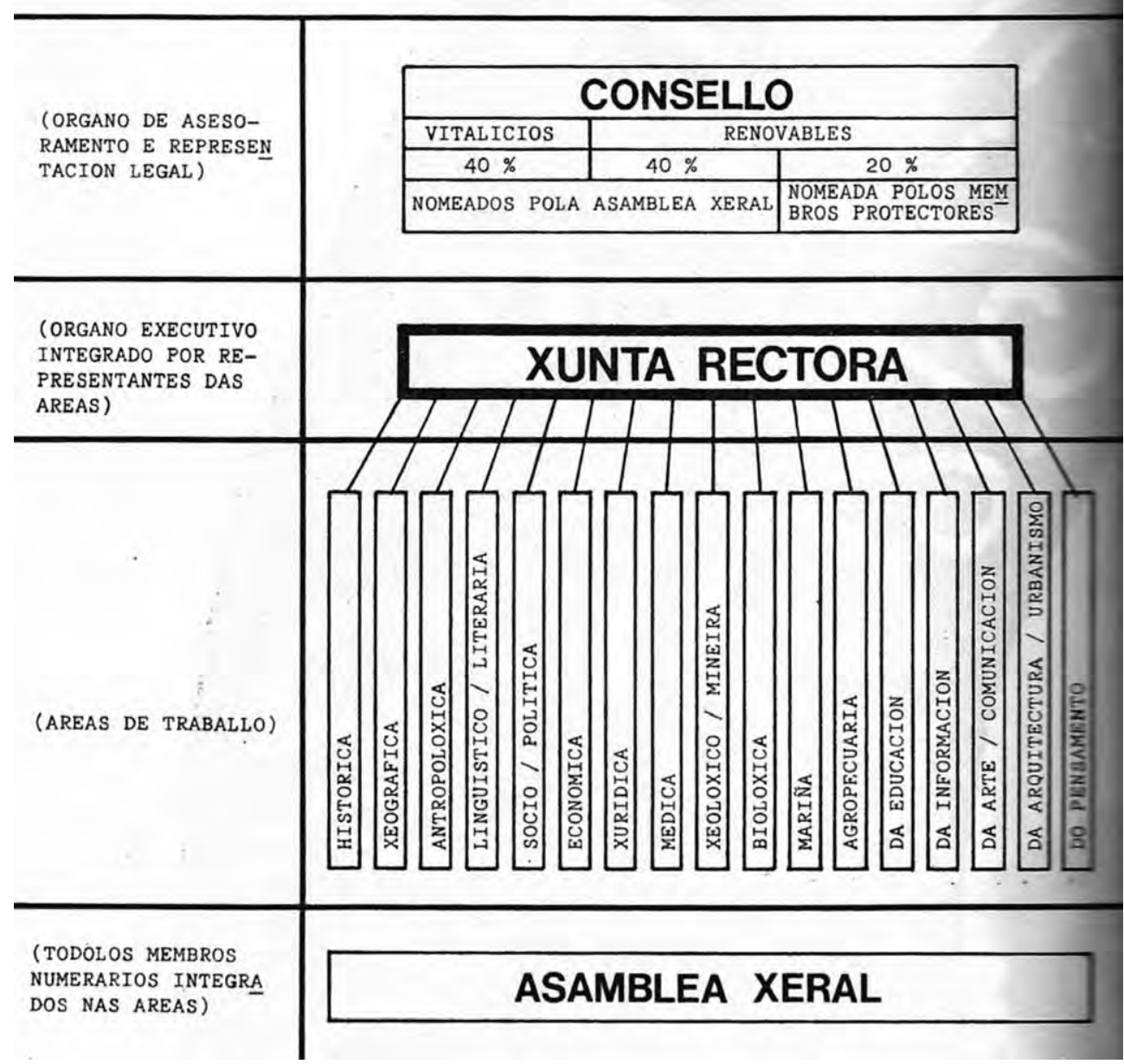

